\title{
Thymocytes induce renal tubular epithelial cells to undergo the epithelial-to-mesenchymal transition
}

\author{
Huajun Sun, ${ }^{1, *}$ Xueyao Wang, ${ }^{2, *}$ Yisha Liu $^{1}$ Shuaixia Yu, ${ }^{1}$ Yue Yang,,${ }^{1}$ Shan $W u,{ }^{3}$ Chengbin Zhang ${ }^{4}$
}

\begin{abstract}
Background: Renal tubulointerstitial fibrosis is known to occur as a result of epithelial cell transformation into myofibroblasts via the epithelial-to-mesenchymal transition (EMT) process. It has been reported that macrophages, regulatory $\mathrm{T}$ (Treg) cells, and gamma delta $\mathrm{T}(\gamma \delta \mathrm{T})$ cells can promote fibrosis via EMT in vivo.
\end{abstract}

Objective: Our study intended to detect whether thymocytes can induce renal tubular cells to undergo the EMT.

Methods: Rat thymocytes were activated by phytohemagglutinin and concanavalin A. The rat renal tubular epithelial cells (NRK-52E) were incubated in a conditioned medium harvested from activated thymocytes or co-cultured with freshly isolated thymocytes for 48 hours. Real-time reverse transcription-polymerase chain reaction, immunofluorescence, and western blotting analysis were used to test the expression of the epithelial and mesenchymal markers in NRK-52E cells. Scratch assay was designed to test the cell migration abilities of NRK-52E cells. Student's t test and oneway analysis of variance test were used for statistical analysis.

Results: The combined stimulation with phytohemagglutinin and concanavalin A activated the primary isolated rat thymocytes. After treatment with conditioned medium or freshly isolated thymocytes, the expression levels of cytokeratin 19 and E-cadherin were downregulated in NRK-52E cells, while the mRNA and protein expression levels of alpha-smooth muscle actin, desmin, and vimentin were upregulated $(P<0.05)$. We found that the cell migration abilities of the induced NRK-52E cells were significantly improved.

Conclusion: Both activated rat thymocytes (more percentage of $\mathrm{CD}^{+} \mathrm{T}$ cells) and freshly isolated thymocytes have promoting effects on the EMT of NRK-52E cells.

Key words: Thymocytes, CD8 ${ }^{+} \mathrm{T}$ cells, NRK-52E cells, Epithelial-to-mesenchymal transition (EMT), Renal fibrosis

From:

Department of Pathology, Sichuan Academy of Medical Sciences \& Sichuan Provincial People's Hospital, China;

Chinese Academy of Sciences Sichuan Translational Medicine Research Hospital, Chengdu, China;

Department of Pathology, Sichuan Provincial People's Hospital, University of Electronic Science and Technology of China, Chengdu, China

2 Department of Nephrology, The First Hospital of Jilin University, Changchun, China

3 The Key Laboratory of Pathobiology, Ministry of Education, China; Bethune Medical College, Jilin University, Changchun, China

${ }^{4}$ Department of Pathology, The First Hospital of Jilin University, Changchun, China

* Contributed equally

Corresponding author:

Chengbin Zhang

Department of Pathology, The First Hospital of Jilin University,

No. 71, Xinmin Street, Changchun City, Jilin Province, 130021, China

E-mail: topzhnagcb@jlu.edu.cn

\section{Introduction}

Renal interstitial fibrosis is a common feature of chronic renal disease and is characterized as pathological lesions caused by renal tubular damage and necrosis, as well as excess deposition of the extracellular matrix (ECM). ${ }^{1,2}$ The excess extracellular matrix deposited in fibrotic kidneys is mainly produced by myofibroblasts. ${ }^{3,4}$ In recent years, the origin of these myofibroblasts has been a subject of intensive investigation and the epithelial-to-mesenchymal transition (EMT) has gained broad acceptance as one of the associated pathogenetic mechanisms. ${ }^{5}$ The chief characteristics of this process include the loss of epithelial markers, such as E-cadherin and cytokeratin in epithelial cells, and expression of mesenchymal and myofibroblast markers, such as desmin and alpha-smooth muscle actin ( $\alpha$-SMA ), ${ }^{6,7}$ accompanied by the elongated morphology, enhanced migratory capacity, and increased production of ECM. Thus, it has been proposed that injured tubular 
epithelial cells undergo EMT to become myofibroblasts and then traverse the tubular basement membrane into the interstitial environment, ${ }^{8}$ resulting in the development of renal interstitial fibrosis.

In addition to macrophages, $\mathrm{T}$ cell infiltration is also observed in acute kidney injury (AKI), where it displays complex functions, and in acute rejection after renal transplantation. ${ }^{9}$ While the common outcome of AKI and acute rejection is renal interstitial fibrosis, ${ }^{10-12}$ severe, frequent acute rejection can accelerate the occurrence of interstitial sclerosis tubular atrophy, ${ }^{10,11}$ thus indicating that there is an association between acute rejection and renal fibrosis. The main histological changes associated with acute rejection include lymphocyte and macrophage infiltration in the interstitial and $\mathrm{T}$ lymphocytes in renal tubules (tubulitis). The severity of tubulitis is often used to describe the severity of acute rejection. ${ }^{13} \mathrm{Re}$ cent reports reveal that macrophages can induce the EMT of human renal tubular epithelial cells in vitro, ${ }^{14}$ and several in vivo studies have shown the possible relationship between $\mathrm{T}$ cell (regulatory T (Treg) cells and gamma delta $\mathrm{T}(\gamma \delta \mathrm{T})$ cells) infiltration and EMT with fibrosis formation. ${ }^{15,16}$ Since many different subtypes of T cells may contribute to the EMT of epithelial cells, we hypothesized that $\mathrm{T}$ lymphocytes, regardless of their subtypes and even including young $\mathrm{T}$ lymphocytes, can induce epithelial cells to undergo the EMT to become myofibroblasts.

\section{Materials and Methods}

\section{Rat thymic-derived lymphocytes}

\subsection{Rat thymic-derived lymphocyte separation and culture in vi-} tro

Male Wistar rats, 230-250 g, were obtained from the Experimental Animal Center of Jilin University, China. The rats were anesthetized by intraperitoneal injection of chloral hydrate and placed into $75 \%$ ethanol for sterilization. After 10 minutes, we resected the thymus tissues from the thoraxes of these rats, cut them into pieces, and ground them in a phosphate-buffered saline (PBS) solution containing $0.5 \%$ penicillin and streptomycin. Small thymus tissue fragments and cells in PBS were ground and filtered through a number 200 mesh sieve. The filtrate below the mesh sieve was collected and the supernatant was removed after centrifugation at 1,200 rpm for 10 minutes. The cell sediment was washed three times in Dulbecco's modified Eagle's medium/high glucose (DMEM-H, Invitrogen, USA) with $10 \%$ fetal bovine serum (FBS, Hyclone, USA) and subsequently maintained in the same medium. The culture flask was changed each time the medium changed in order to discard the adherent epithelial reticular cells. This study was approved by the Ethics Committee of Bethune Medical College and followed all the regulatory standards.

\subsection{Analysis of the rat thymic-derived lymphocytes}

We performed flow cytometry to analyze the expression levels of the cluster of differentiation 4 (CD4) and cluster of differentiation 8 (CD8) antigens to observe their subgroup distribution in freshly isolated cells. Approximately $1 \times 10^{6}$ cells/sample were centrifugally washed twice with cold PBS at $4^{\circ} \mathrm{C}$ and then treated with fluorescein isothiocyanate (FITC)-conjugated anti-rat CD4 Antibody (1 ng/ml) and phycoerythrin (PE)-conjugated anti-rat CD8 Antibody (0.75 ng/ $\mathrm{ml}$ ) (BioLegend, USA). FITC mouse immunoglobulin G 1 (IgG1), $\kappa$ Isotype Ctrl Antibody and PE mouse IgG1, $\kappa$ Isotype Ctrl Antibody (BioLegend, USA) were used for isotype control. After incubation at $4^{\circ} \mathrm{C}$ for 60 minutes, centrifugally washed twice and resuspended with $500 \mathrm{uL}$ PBS, the thymocyte subpopulations were detected by Flow cytometry (FACS, Becton Dickinson, San Jose, CA) and the data were analyzed with CellQuest software (Becton Dickinson).

Later, the thymic-derived lymphocytes were cultured in DMEM-H modified with $10 \%$ FBS containing $5 \mu \mathrm{g} / \mathrm{mL}$ of phytohemagglutinin (PHA) and $10 \mu \mathrm{g} / \mathrm{mL}$ of concanavalin A (ConA) for stimulation. ${ }^{17,18}$ The thymic-derived lymphocytes incubated in 10\% FBS DMEM-H were used as the control group. We observed the cell morphology of these two groups at 0 hours, 24 hours, and 72 hours. Trypan blue staining was performed to calculate the cell viability at 72 hours. For cell cycle analysis, after 24 hours, we washed the cells with cold PBS and used 70\% ethanol to fix the cell pellets. Then, we treated the cells with RNase (TaKaRa, Japan) and 0.01\% Triton-X 100 (DingGuo, Beijing, China), followed by staining with propidium iodide (Sigma, USA). The DNA contents were then measured using a flow cytometer. We also analyzed the expression levels of CD4 and CD8 antigens in the two groups of thymic-derived lymphocytes by flow cytometry. The rat peripheral blood lymphocytes isolated with lymphocyte separation medium (Sigma, USA) were employed as a positive control and the experiment method was as described above.

We detected the concentrations of Interleukin-2 (IL-2) and transforming growth factor- $\beta 1$ (TGF- $\beta 1$ ) in the thymocyte supernatant. After thymocytes were stimulated with PHA and ConA for 24 hours, both the control and stimulated groups were incubated in a serum-free medium and the culture supernatants were collected at 24 hours and 48 hours. The concentrations of IL- 2 and TGF- $\beta 1$ in the thymocyte supernatant were detected by the enzyme-linked immunosorbent assay (ELISA) according to the instructions mentioned in the ELISA Kit (RD Systems, USA).

\subsection{Preparation of conditioned medium}

For activation, the thymic-derived lymphocytes were cultured in DMEM-H with $10 \%$ FBS containing $5 \mu \mathrm{g} / \mathrm{mL}$ of PHA and $10 \mu \mathrm{g} / \mathrm{mL}$ of ConA for 24 hours, washed three times with serum-free DMEM-H, and cultured in serum-free DMEM-H for another 48 hours. The medium from the final wash was collected, filtered through a $0.22 \mu \mathrm{m}$ filter, and used as the control medium. After 48 hours, the culture medium was collected, filtered, and used as conditioned medium. ${ }^{19}$

\section{NRK-52E cells}

\subsection{NRK-52E cell line}

The rat renal proximal tubular epithelial cell line, NRK52E, was purchased from the Institute Cell Library in Shanghai, China and was maintained in DMEM-H modified with $10 \%$ FBS. 


\subsection{NRK-52E cell line treatment}

We designed two experiments to detect whether the rat thymic-derived lymphocytes can induce the EMT of NRK$52 \mathrm{E}$ cells.

(1) We seeded NRK-52E cells $\left(2 \times 10^{7}\right.$ cells $\left./ \mathrm{mL}\right)$ into flasks. After the cells adhered to the wells, we replaced the supernatant of cells in the induced group with the treatment medium containing 10\% FBS, 45\% DMEM-H, and 45\% conditioned medium (details in section 1.3 Preparation of conditioned medium), while the control group was treated with 10\% FBS, 45\% DMEM-H, and 45\% control medium (details in section 1.3 Preparation of conditioned medium). NRK-52E cells were collected after 48 hours.

(2) We seeded NRK-52E cells $\left(2 \times 10^{7}\right.$ cells/mL $)$ into sixwell plates and placed a suspension culture device in each well. After the cells adhered to the wells, we added double numbers of freshly isolated thymic-derived lymphocytes and the corresponding volume of culture medium to the suspension culture device. Cells normally cultured in DMEM-H modified with $10 \%$ FBS were used as the control group. NRK52E cells were collected after 48 hours.

\section{Detection of NRK-52E cells}

We used cytokeratin 19 (CK19) and E-cadherin (E-Ca) to detect the epithelial phenotype expression of NRK-52E cells, while a-SMA, desmin, and vimentin were chosen to observe the expression of mesenchymal cell markers in NRK-52E cells.

\subsection{Morphological observation}

After 48 hours of culture, the cell growth morphologies of the control group and the induced group were observed under an inverted microscope (Olympus, Japan). Fifteen randomly selected $400 \times$ fields of vision in the two groups of cells were taken. The number of fusiform cells and the total number of NRK-52E cells in each field were counted and the percentage of fusiform cells in each field was also calculated.

\subsection{Real-time reverse transcription-polymerase chain reaction (RT-PCR) analysis}

The total RNA was isolated from NRK-52E cells using a Total RNA Extraction Kit (TIANGEN, Beijing, China) and reverse transcribed to cDNA using a Reverse Transcriptase Kit (TaKaRa, Japan). The housekeeping gene, glyceraldehyde-3-phosphate dehydrogenase (GAPDH), was used as an internal control. For real-time RT-PCR, the PCR mixture contained $5 \mu \mathrm{L}$ of cDNA $(1 \mathrm{ng} / \mu \mathrm{g}), 4 \mu \mathrm{L}$ of each primer $(2$ $\mu \mathrm{M}), 12.5 \mu \mathrm{L}$ of SYBR Green qPCR Mix (Roche), and $3.5 \mu \mathrm{L}$ of double-distilled water. Amplification was performed using the ABI 7300 Real-time PCR system. We used the following formula to calculate the mRNA levels: $2^{\Delta \mathrm{Ct}}$, where $\Delta \mathrm{Ct}$ indicates the difference in the threshold cycle between GAPDH and the target genes. The primers were purchased from Sangon Biotech Company Limited (Shanghai, China) (the details are shown in Table 1).

\subsection{Immunofluorescence analysis}

NRK-52E cells cultured on glass coverslips were washed with serum-free DMEM three times, fixed with $4 \%$ paraformaldehyde, and permeabilized with $0.2 \%$ Triton X-100 in PBS. We used $10 \%$ normal goat serum to block the non-specific binding at room temperature for 30 minutes. Then, the cells were incubated with primary antibodies against CK19, E-Ca, a-SMA, desmin and vimentin, (the details are displayed in Table 2). After washing the suspension three times, Alexa Fluor 488-conjugated anti-rabbit or anti-mouse antibodies (Invitrogen, USA) were added, followed by counterstaining with Hoechst 33342 (Invitrogen, USA) for nuclear staining. Then, the sections were examined for the intensity of staining reaction, which was graded as negative (-), mildly positive $(+)$, moderately positive $(++)$, and strongly positive $(+++)$. Images were acquired using laser confocal microscopy (Olympus, Japan) and Adobe Photoshop CS2 9.0 was used for processing the images.

Table 1. Primer sets used in Real-Time Reverse Transcription-PCR Analysis.

\begin{tabular}{|c|c|c|c|c|}
\hline Genes & Primers & Sequences & $\begin{array}{l}\text { Product } \\
\text { size (bp) }\end{array}$ & Gene ID. \\
\hline \multirow[t]{2}{*}{ GAPDH } & Forward & 5'-CCAGCATATTCAATTCCATGA-3' & 180 & 24383 \\
\hline & Reverse & 5'-GGTTGCCTAGTTTCATTCTCA-3' & & \\
\hline \multirow[t]{2}{*}{ CK19 } & Forward & 5'-CTCTGCCATCCACGATCTTACG-3' & 125 & 360626 \\
\hline & Reverse & 5'-GTCAGAGCTGGCACAAACTCG-3' & & \\
\hline \multirow[t]{2}{*}{ a-SMA } & Forward & 5'-CCAGTTGGTGATGATGCCGTG-3' & 175 & 81634 \\
\hline & Reverse & 5'-GCTGCTCCAGCTATGTGTGAAGAG-3' & & \\
\hline \multirow[t]{2}{*}{ Vimentin } & Forward & 5'-TCCATCTCTGGTCTCAACCG-3' & 155 & 81818 \\
\hline & Reverse & 5'-GGCTCGTCACCTTCGTGAATAC-3' & & \\
\hline
\end{tabular}

Abbreviations: GAPDH: glyceraldehyde-3-phosphate dehydrogenase, CK19: cytokeratin 19, a-SMA: alpha-smooth muscle actin. 
Table 2. The information, application and scoring results in two EMT promoting experiments of Immunofluorescence staining primary antibodies.

\begin{tabular}{|c|c|c|c|c|c|c|c|c|}
\hline \multirow[b]{2}{*}{ Antibody } & \multirow[b]{2}{*}{ Source } & \multirow[b]{2}{*}{ Dilution } & \multirow[b]{2}{*}{ Repair method } & \multirow[b]{2}{*}{ Company } & \multicolumn{2}{|c|}{ Conditioned medium-induced EMT } & \multicolumn{2}{|c|}{ Freshly thymocytes-induced EMT } \\
\hline & & & & & Control group & Induced group & Control group & Induced group \\
\hline CK19 & rabbit & $1: 50$ & Hot repair ${ }^{\#}$ & Bio & +++ & + & +++ & +++ \\
\hline $\mathrm{E}-\mathrm{Ca}$ & rabbit & $1: 50$ & Hot repair ${ }^{\#}$ & Bio & & & + & - \\
\hline a-SMA & mouse & $1: 100$ & Enzyme repair ${ }^{*}$ & Abcam & - & + & - & + \\
\hline Desmin & rabbit & $1: 100$ & Hot repair ${ }^{\#}$ & Bio & + & +++ & + & ++ \\
\hline Vimentin & rabbit & $1: 100$ & Enzyme repair ${ }^{*}$ & Bio & & & + & +++ \\
\hline
\end{tabular}

Abbreviation: CK19: cytokeratin 19, E-Ca: E-cadherin, a-SMA: alpha-smooth muscle actin.

Bio: Biosynthesis, Beijing, China, Abcam: Abcam, Cambridge, UK.

${ }^{*}$ Hot repair, $0.1 \mathrm{~m}$ citric acid buffer solution, $\mathrm{PH}: 6.0,98^{\circ} \mathrm{C}$ for 10 minutes.

${ }^{\star}$ Enzyme Repair, compound digestive enzyme (Maixin, Fuzhou, China) for 8 minutes at room temperature.

\subsection{Western blotting analysis}

NRK-52E cells were lysed with sodium dodecyl sulphate (SDS) sample buffer (DingGuo, Beijing, China). The protein concentration was determined using a BCA Protein Assay Kit (Beyotime, Shanghai, China). A mixture of the cell lysate and $5 \mathrm{x}$ loading buffer was heated at $100^{\circ} \mathrm{C}$ and loaded on $10 \%$ SDS-polyacrylamide gels. After electrophoresis, the proteins were electro-transferred onto polyvinylidene fluoride (PVDF) membranes using the Mini Trans-Blot Electrophoretic Transfer Cell (Bio-Rad, Hercules, CA). For immunodetection, the membranes were blocked with 5\% skim milk for 1 hour at room temperature and incubated overnight at $4^{\circ} \mathrm{C}$ with the following primary antibodies: rabbit monoclonal anti-CK19 (Abcam, UK), rabbit monoclonal anti-SMA (Abcam, UK), and monoclonal anti-GAPDH (Abcam, UK). Binding of the primary antibodies was followed by incubation for 1 hour at $37^{\circ} \mathrm{C}$ with secondary horseradish peroxidase-conjugated IgG in $1 \%$ skim milk. The bands were visualized using the BeyoECL Plus Kit (Beyotime, Shanghai, China). Image J v.1.44 software (USA) was used to analyze the images, gray value of GAPDH for correction, and relative quantity of the gray value of the target protein/GAPDH for statistical analysis.

\subsection{Scratch assay}

After confluence, both the control and induced group of NRK-52E cells were scratched by a straight line using a sterile pipette tip. After that, PBS was utilized to wash the cells to remove the cell debris. Then, the cells were cultured with serum free DMEM-H at $37^{\circ} \mathrm{C}$. Photographs of the scratch wounds were recorded using an inverted microscope at 0 and 24 hours to investigate and analyze the scratch wound assay. The scratch area was measured using the Image-J software.

\section{Statistical analysis}

All experiments were repeated three time, and the results are expressed as the mean \pm standard deviation (SD). Student's $t$ test and one-way analysis of variance (ANOVA) test were used to compare parallel groups using SPSS v.15.0 software (Chicago, USA). $P<0.05$ was considered statistically significant.

\section{Results}

1. Rat thymic-derived lymphocytes activated by $P H A$ and ConA in vitro.

The isolated thymocytes of rats were cultured in DMEM-H containing $10 \%$ FBS. Under an inverted microscope, the thymocytes appeared as single oval-shaped cells of uniform size (Figure 1, A-B). The results of flow cytometry antigen detection showed that $83.1 \%$ of the cells were $\mathrm{CD} 4^{+} \mathrm{CD} 8^{+}$double-positive immature lymphocyte cells, $12.2 \%$ were $\mathrm{CD}^{+}$ lymphocyte cells, $2.4 \%$ were $\mathrm{CD}^{+}$lymphocyte cells, and $2.3 \%$ were fully negative cells (Figure 1, C). The proportion of the isolated thymocyte subpopulation was consistent with the distribution of cells in the thymus tissue.

The rat thymic-derived lymphocytes were treated with PHA $(5 \mu \mathrm{g} / \mathrm{mL})$ and ConA $(10 \mu \mathrm{g} / \mathrm{mL})$. After 24 hours, the lymphocytes in the treatment group adhered to each other and became cell colonies but those in the control group were distributed uniformly in the medium (Figure 1, D-E). After 72 hours, the number of cells in the control group decreased remarkably (Figure 1, F). Trypan blue staining showed that as many as $55 \%$ of the cells had died. While cells in the stimulation group grew well in large colonies (Figure 1, G), trypan blue staining showed that only $5 \%$ of these cells died. Cell cycle analysis revealed that the percentages of cells in the G2 and $S$ phases were $18.18 \pm 1.0 \%$ in the control group (Figure $\mathbf{1}, \mathbf{H}$ ) and $32.5 \pm 2.07 \%$ in the stimulation group (Figure 1, I), which was significantly higher than that in the control group $(P=0.0037)$ (Figure 1, J). These data indicate that stimulation for 24 hours with PHA and ConA can induce the rat thymic-derived lymphocytes to undergo mitosis. We checked $\mathrm{CD}^{+}, \mathrm{CD}^{+}$, and $\mathrm{CD}^{+} \mathrm{CD}^{+}$cell subsets in the stimulation and control groups after 24 hours and the rat peripheral blood lymphocytes were employed as the positive control. The percentage of $\mathrm{CD}^{+} \mathrm{CD}^{+}$cells was only $6.06 \pm 1.52 \%$ in the rat peripheral blood lymphocytes, thus showing that the majority of mature $\mathrm{T}$ lymphocytes were either $\mathrm{CD} 4^{+}$cells or $\mathrm{CD}^{+}$cells, while all of the $\mathrm{CD} 4^{+} \mathrm{CD} 8^{+}$cells were immature $\mathrm{T}$ lymphocytes (Figure 2, A). The percentages of $\mathrm{CD} 4^{+} \mathrm{CD} 8^{+}$ cells were $75.9 \pm 1.43 \%$ in the stimulation group and 90.98 $\pm 0.66 \%$ in the control group $(P=0.0007)$. The proportion of $\mathrm{CD}^{+} \mathrm{T}$ cells in the thymocytes of the stimulation group 

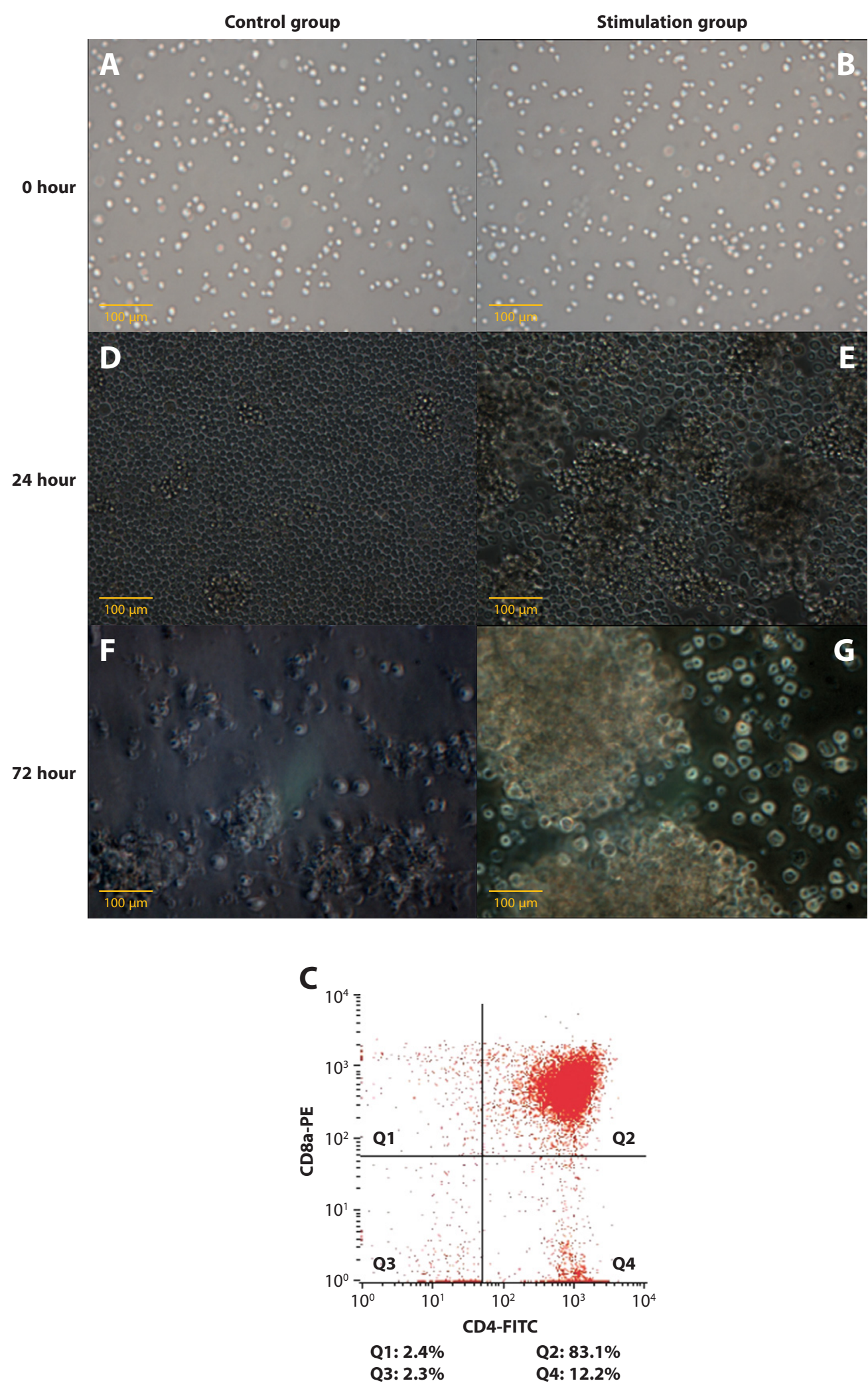

Figure 1. Rat thymic-derived lymphocytes were activated by phytohemagglutinin (PHA) and concanavalin A (ConA) in vitro (Morphological change and Cell cycle analysis).

A, B, D-G: Phase-contrast images of lymphocytes in the control group at 0 hours (A), 24 hours (D), and 72 hours (F) or the lymphocytes treated with PHA $(10 \mu \mathrm{g} / \mathrm{mL})$ and ConA $(5 \mu \mathrm{g} / \mathrm{mL})$ at 0 hours (B), 24 hours (E), and 72 hours $(\mathrm{G})$, Bar $=100 \mu \mathrm{m}$.

C: CD4 and CD8 subgroup distribution of freshly isolated cells. 


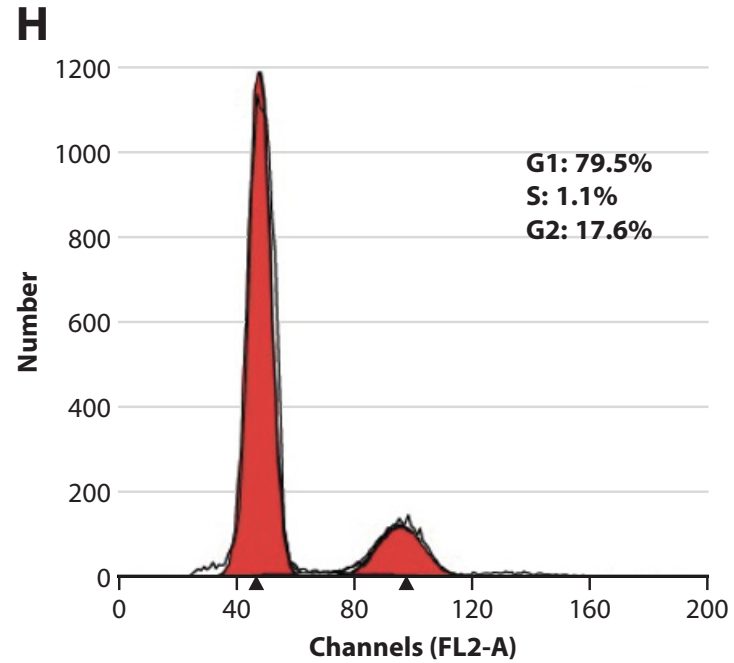

Channels (FL2-A)
I

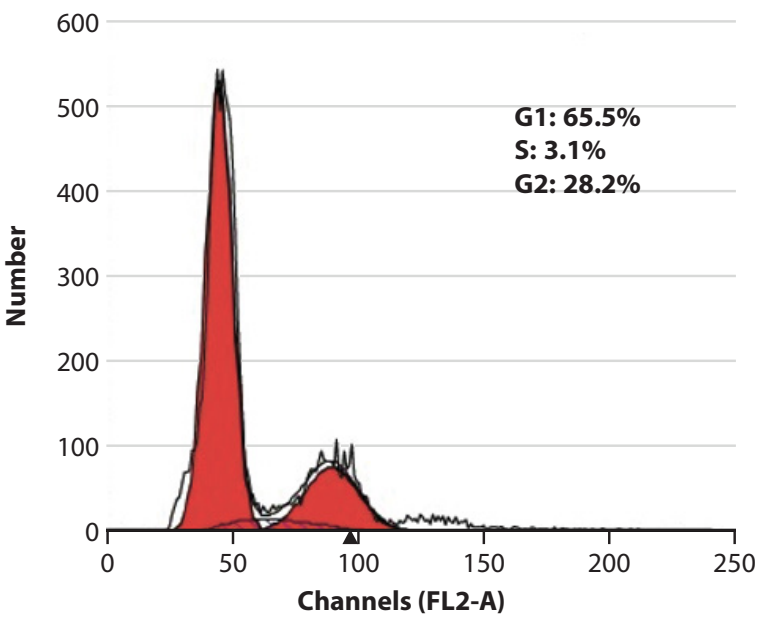

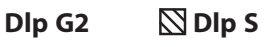

J

Figure 1. (Continued)

Dlp G1

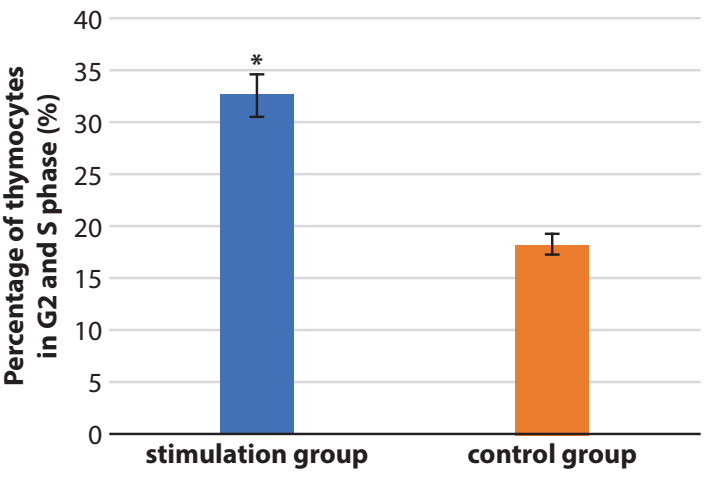

H-I: Cell cycle analysis of untreated lymphocytes $(\mathrm{H})$ or lymphocytes in the stimulation group (I) for 24 hours.

J: The percentage of cells in the G2 and S phases in the stimulation group was higher than that of the control group. ${ }^{\star} P<0.05$

A
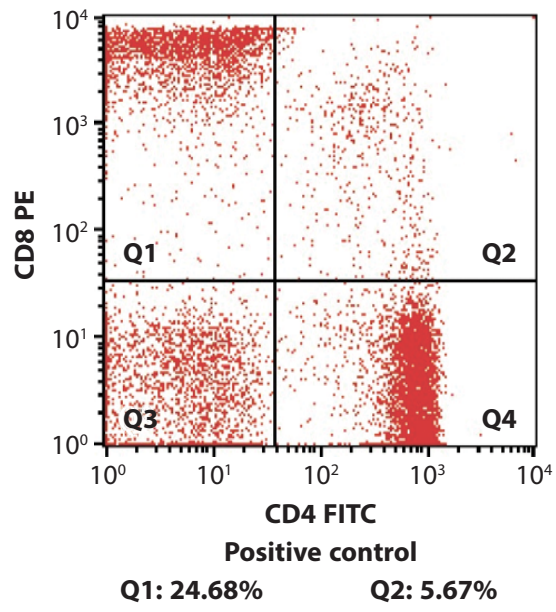

Q3: $22.79 \% \quad$ Q4: $46.86 \%$
B

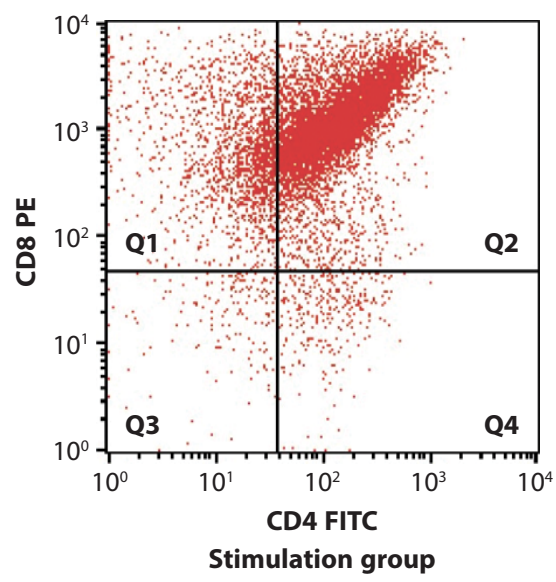

Q1: $19.33 \%$ Q3: $2.99 \%$
Q2: $74.46 \%$

Q4: $3.22 \%$

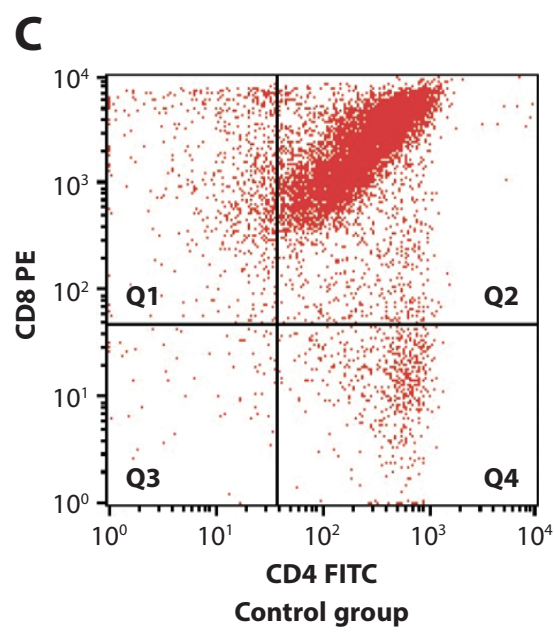

Q1: $4.77 \%$ Q3: $0.01 \%$

Q2: $91.44 \%$ Q4: $3.78 \%$

Figure 2. Rat thymic-derived lymphocytes were activated by PHA and ConA in vitro (Subtype distribution and Cytokine secretion).

A: Peripheral blood lymphocytes were used as the positive control.

B-C: Expression levels of CD4 and CD8 antigens on thymic-derived lymphocytes in the stimulation (B) and control groups (C). 
D

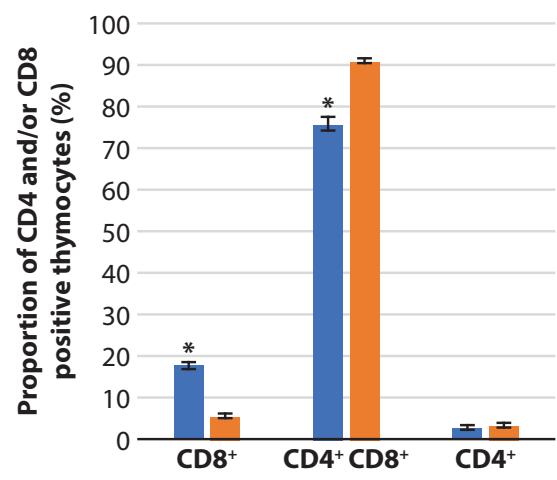

$\mathbf{E}$

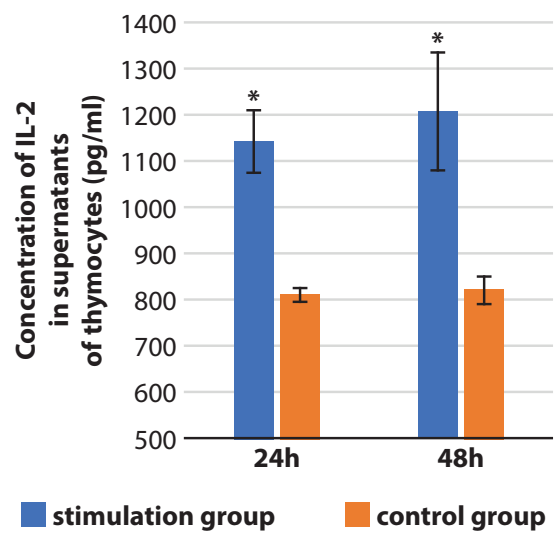

$\mathbf{F}$

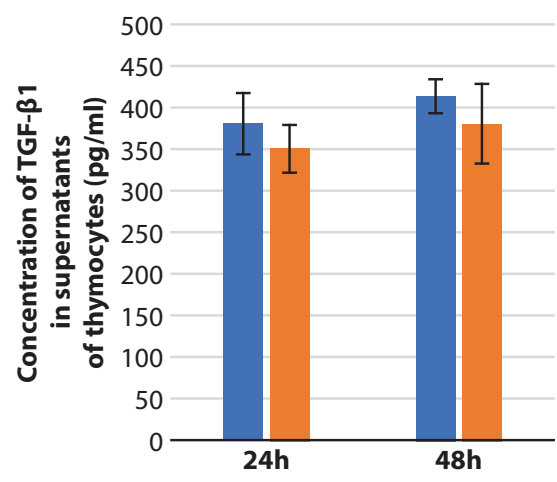

Figure 2. (Continued)

D: After activation, the proportion of mature T lymphocytes (especially CD8 ${ }^{+}$cytotoxic $\mathrm{T}$ cells) was increased.

E: After activation for 24 and 48 hours, the concentration of interleukin-2 (IL-2) in the supernatants of the stimulation group thymocytes was significantly higher than that in the corresponding control group thymocytes.

F: There was no significant difference in the concentration of the transforming growth factor- $\beta 1$ (TGF- $\beta 1$ ) between the control and stimulation groups. ${ }^{\star} P<0.05$

was $17.99 \pm 0.90 \%$, which was significantly higher than the proportion of these cells in the thymocytes of the control group $(5.69 \pm 0.63 \%)(P=0.0008)$ (Figure 2, B-D).

We also collected the supernatants and determined the concentrations of IL-2 (Figure 2, E) and TGF- $\beta 1$ (Figure 2, F) in them. A serum-free culture was performed for 24 hours. In the stimulation group, the concentration of IL-2 in the culture medium was found to be $1140.51 \pm 64.21 \mathrm{pg} / \mathrm{mL}$, while it was only $808.40 \pm 13.94 \mathrm{pg} / \mathrm{mL}$ in the corresponding control group $(P=0.0002)$. After incubation in the serum-free culture medium for 48 hours, the concentration of IL-2 in the thymocytes of the stimulation group was $1202.73 \pm 129.79 \mathrm{pg} /$ $\mathrm{mL}$, which was significantly higher than that observed in the thymocytes of the corresponding control group (817.8 \pm 28.65 $\mathrm{pg} / \mathrm{mL})(P=0.0062)$. After incubation in the serum-free culture for 24 hours, the concentration of TGF- $\beta 1$ was $382.88 \pm$ $36.82 \mathrm{pg} / \mathrm{mL}$ in the stimulation group and $353.50 \pm 28.99 \mathrm{pg} /$ $\mathrm{mL}$ in the control group. After 48 hours, the concentration of TGF- $\beta 1$ in the culture medium was $417.15 \pm 20.29 \mathrm{pg} / \mathrm{mL}$ in the stimulation group and $382.03 \pm 48.07 \mathrm{pg} / \mathrm{mL}$ in the corresponding control group. There was no significant difference in the concentration of TGF- $\beta 1$ between the stimulation and control groups after 24 and 48 hours $(P=0.2452$ and $P=$ 0.2151 , respectively).

The results showed that after 24 hours of combined stimulation with PHA and ConA, the growth pattern of the rat thymocytes changed, their proliferation ability was enhanced, the proportion of mature $\mathrm{T}$ lymphocytes (especially $\mathrm{CD}^{+}$ cytotoxic $\mathrm{T}$ cells) increased, and they gained the function of secreting the cytokine, IL-2. The above results indicate that combined stimulation with PHA and ConA for 24 hours is sufficient to activate the primary isolated rat thymocytes.

\section{Conditioned medium induced the EMT in NRK-52E cells}

The NRK-52E cells were incubated in the treatment medium and control medium as described previously. After 48 hours, NRK-52E cells showed typical cobblestone-like morphology in the control group and the adjacent cells appeared to be closely connected when observed under high-power microscope. In the induction group, some of the cells showed short fusiform or polyangular changes, where the cell space appeared enlarged and the cell membrane had sharp protrusions and loose intercellular cohesion when observed under a high-power microscope. These phenomena showed that the cells changed morphologically from cuboidal-shaped clustered cells to spindle-shaped scattered fibroblast-like cells (Figure 3, A-B). The results of statistical analysis showed that the proportion of fusiform cells per field $(\times 400)$ of the NRK-52E cells was $61.05 \pm 4.33 \%$ in the induction group and $13.22 \pm$ $1.72 \%$ in the control group. The percentage of spindle cells in the induction group was significantly higher than that in the control group $(P=0.0008)$.

The results of real-time RT-PCR are shown in Figure 3, C. The expression of CK19 mRNA in the NRK-52E cells was significantly decreased after 48 hours of induction, which was only approximately $26.8 \pm 7.50 \%$ of the expression of the CK19 mRNA in the cells of the control group $(P=0.0004)$. At the same time, the mRNA expression levels of $\alpha$-SMA and vimentin increased significantly in the induced group and they were $1.81 \pm 0.20$ times $(P=0.0059)$ and $1.89 \pm 0.25$ times $(P$ $=0.0084$ ) higher than that in the control group, respectively.

We performed immunofluorescence and western blotting analysis to test the expression of the epithelial markers and mesenchymal markers in the NRK-52E cells. Immunofluorescence analysis revealed that after 48 hours of incubation in treatment medium, NRK-52E cells had reduced CK19 expression (Figure 3, D-E), de novo a-SMA expression (Figure 3, F-G), and increased desmin expression (Figure 3, H-I). 


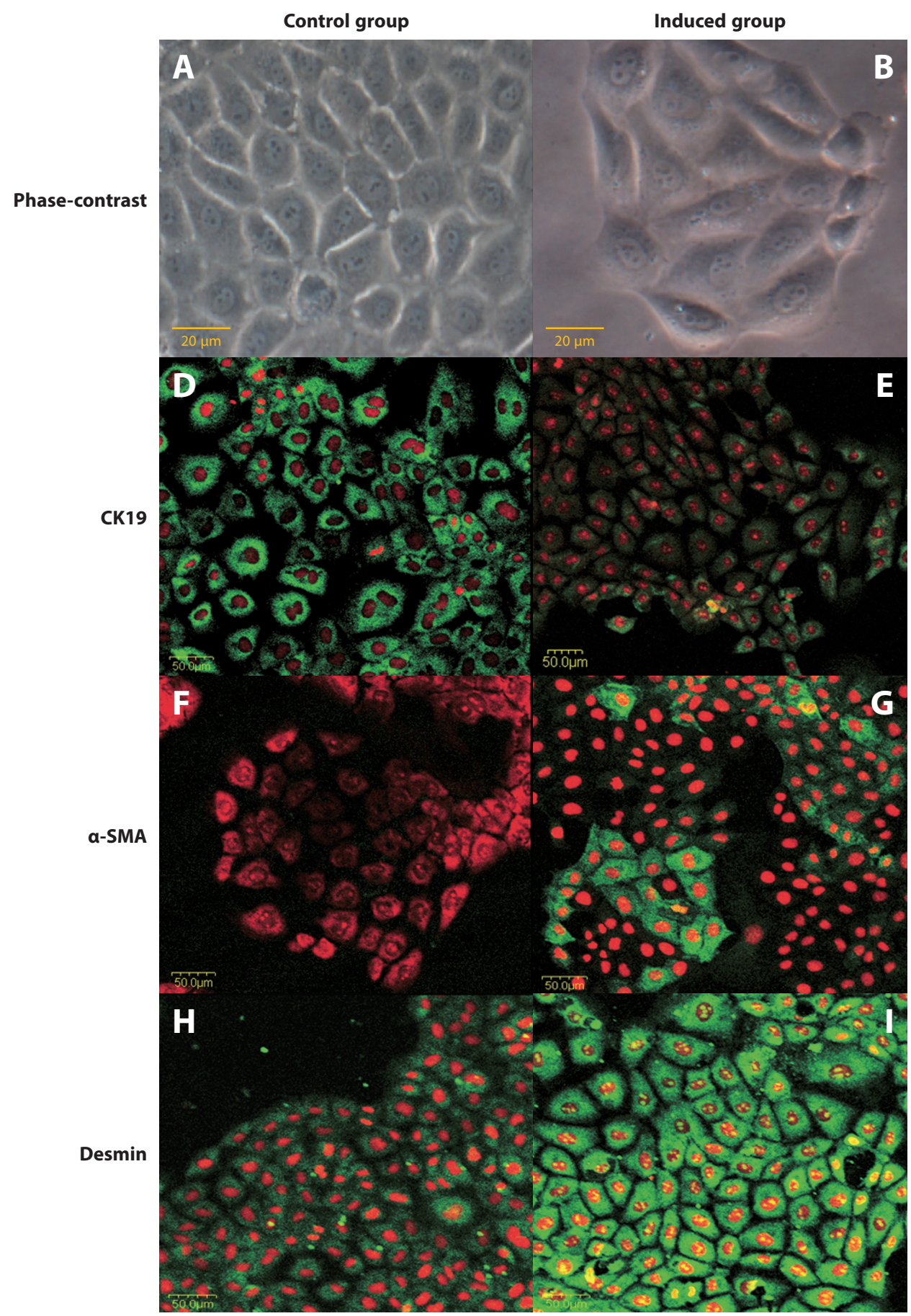

Figure 3. Conditioned medium induced the EMT of NRK-52E cells.

A-B: Phase-contrast images of the NRK-52E cells incubated in the control medium (A) and treatment medium (B) for 48 hours, Bar $=20 \mu \mathrm{m}$.

D-I: Immunofluorescence image showing the expression levels of CK19, a-SMA, and desmin in NRK-52E cells, Bar $=50 \mu \mathrm{m}$. 
C

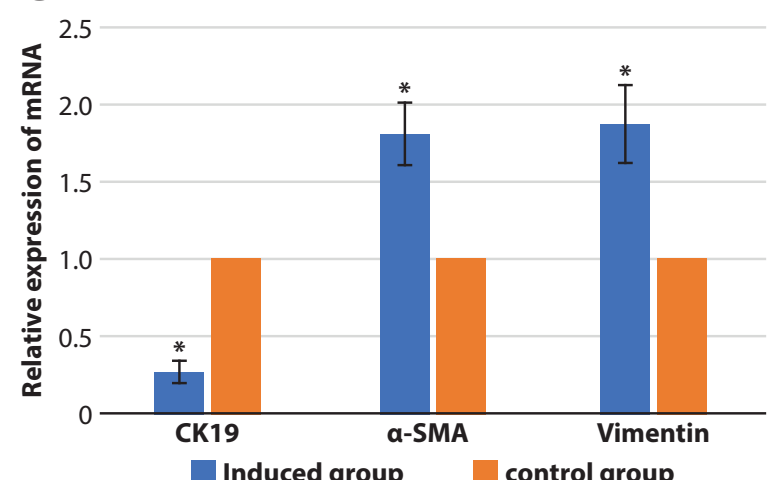

K

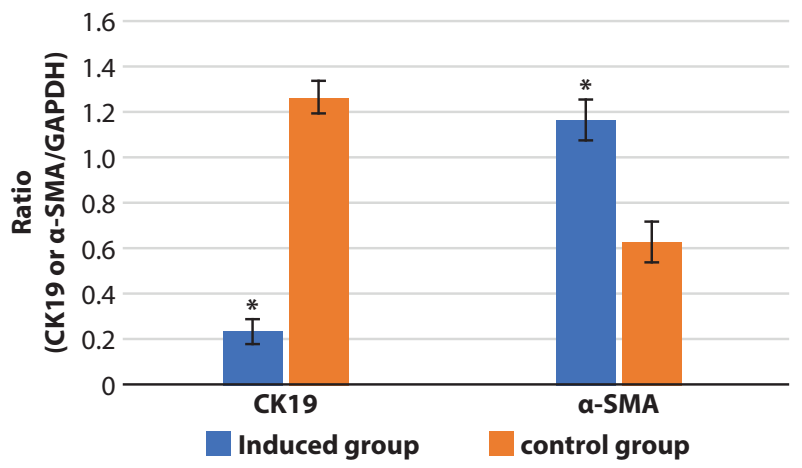

M

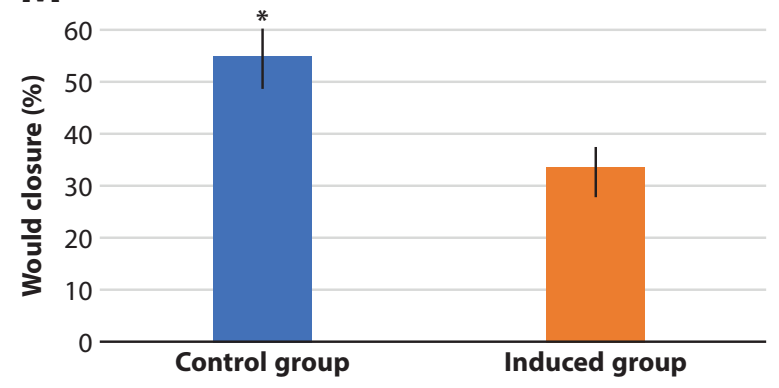

J

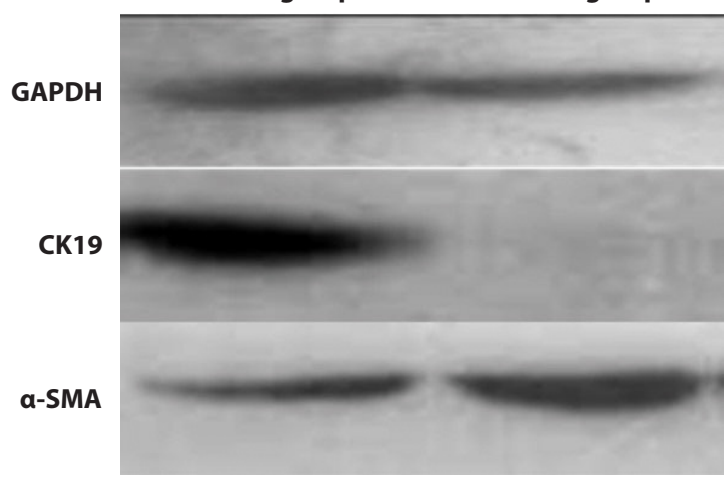

L
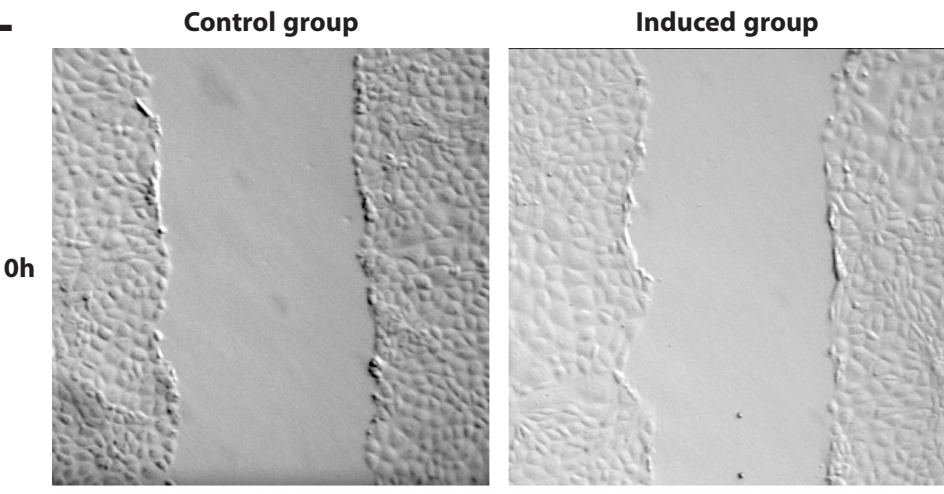

$24 h$
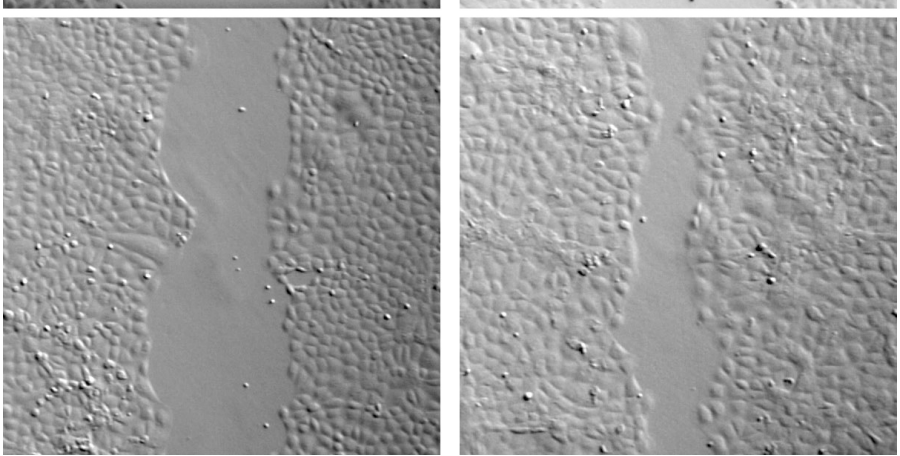

Figure 3. (Continued)

C: The expression levels of cytokeratin 19 (CK19), alpha-smooth muscle actin (a-SMA), and vimentin in NRK-52E cells in the control group and induced group were quantified by real-time reverse transcription-polymerase chain reaction (RT-PCR).

J-K: Western blotting analysis of CK19 and a-SMA versus glyceraldehyde-3-phosphate dehydrogenase (GAPDH) as the internal control.

L-M: Scratch assay indicated that the extent of wound closure in NRK-52E cells of the induced group was higher than that of the control group after 24 hours. ${ }^{\star} P<0.05$

The detailed scoring results are displayed in Table 2. Western blotting analysis of the expression levels of CK19 and a-SMA was also performed in NRK-52E cells. GAPDH was used as an internal reference protein for correction of the gray value (Figure 3, J). The results showed that after 48 hours of induction, the relative expression of the CK19 protein in the induced group was significantly downregulated $(0.23 \pm 0.06)$ compared with that in the control group $(1.27 \pm 0.07)(P=$ 0.0001 ) and the relative expression of the $\alpha$-SMA protein in cells of the induced group was significantly higher $(1.17 \pm$ $0.08)$ than that in the control group $(0.63 \pm 0.09)(P=0.0032)$ (Figure 3, K).
Twenty four hours after the NRK-52E cells were scratched, in vitro scratch assay indicated that the extent of wound closure was much higher in NRK-52E cells of the induced group $(54.66 \pm 4.52 \%)$ than those of the control group (33.70 \pm $3.67 \%)(P=0.0069)$, as shown in Figure 3, L-M.

The results showed that the cellular morphology changed when the NRK-52E cells were induced by treatment medium for 48 hours, the expression of their epithelial cell phenotype was decreased (or lost), and the mesenchymal cell phenotype was expressed simultaneously. The migration ability of the NRK-52E cells also improved significantly. This means that NRK-52E cells had undergone the EMT. 

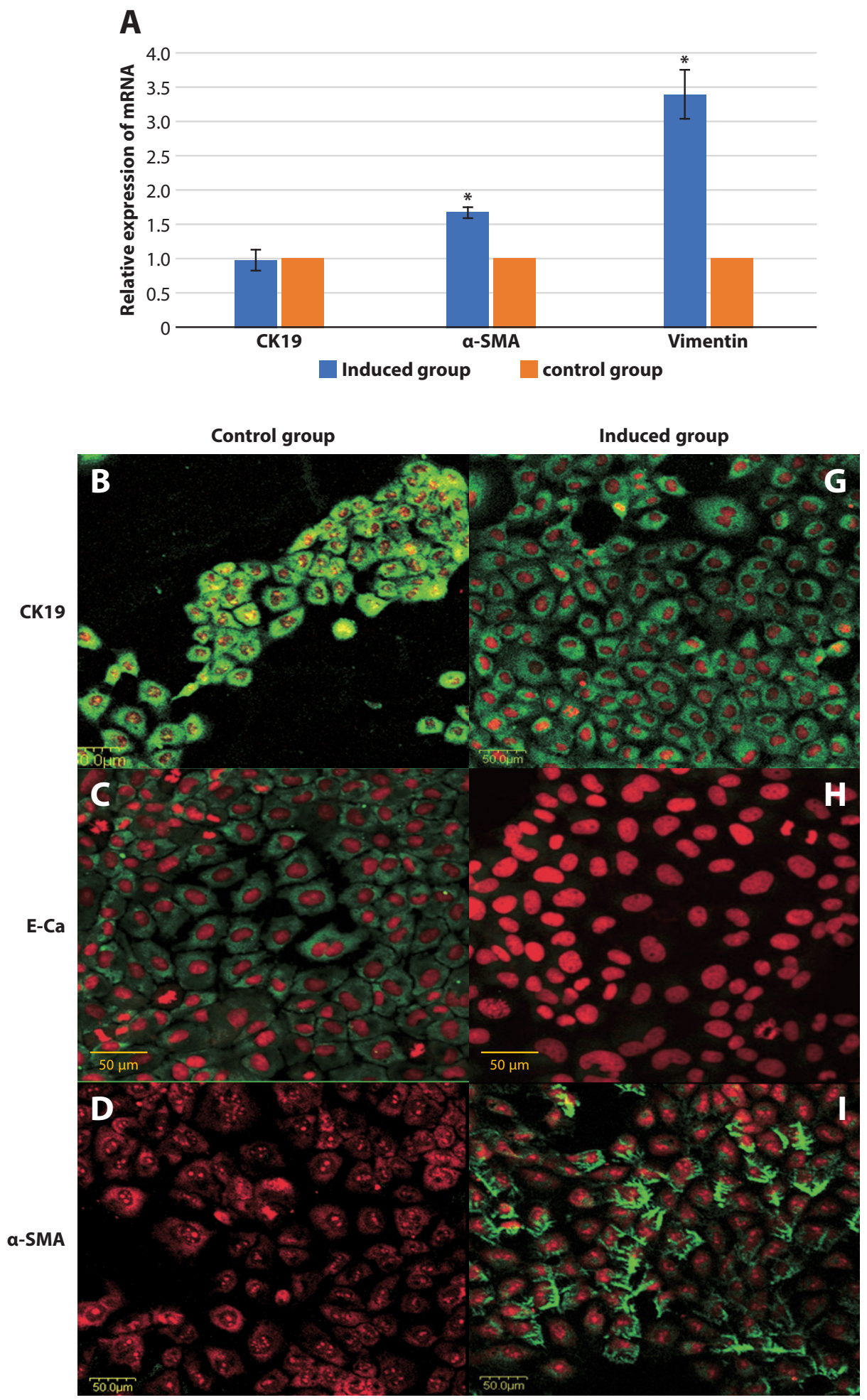

Figure 4. Thymic-derived lymphocytes induce NRK-52E cells to undergo the EMT.

A: Real-time RT-PCR analysis revealed the expression of CK19 and increased expression of $\alpha$-SMA and vimentin in the NRK52E cells co-cultured with thymic-derived lymphocytes for 48 hours. ${ }^{\star} P<0.05$.

B-K: Immunofluorescence staining for CK19 (B, G), E-cadherin (E-Ca) (C, H), a-SMA (D, I), desmin (E, J), and vimentin (F, K) in the NRK-52E cells co-cultured with thymic-derived lymphocytes and the control group for 48 hours, Bar $=50 \mu \mathrm{m}$. 


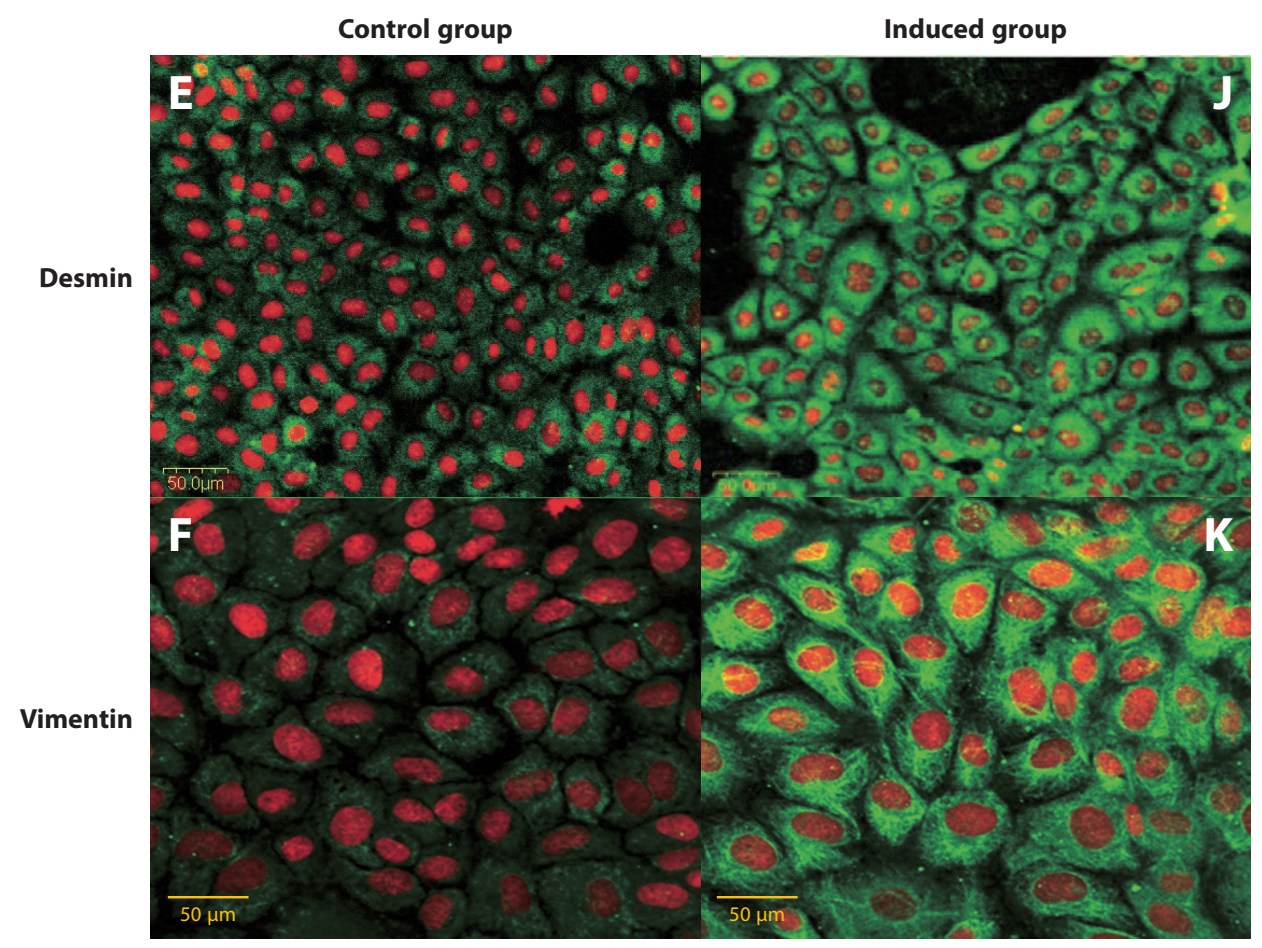

Figure 4. (Continued)

\section{The thymic-derived lymphocyte-induced NRK-52E cells undergo the EMT}

NRK-52E cells were co-cultured with freshly isolated thymic-derived lymphocytes for 48 hours. The results of cell counting and statistical analysis showed that the proportion of fusiform cells per high-power visual field $(\times 400)$ in the control group was only $9.45 \pm 1.86 \%$, while the proportion of spindle cells in the induced group was $68.39 \pm 7.18 \%$, which was significantly higher than that in the control group $(P=$ 0.0011).

The phenotypic changes of the two groups were detected by real-time RT-PCR (Figure 4, A). The amount of CK19 mRNA in the induced group was approximately 98.75 $\pm 15.15 \%$ of that in the control group and there was no significant difference between the two groups $(P=0.8954)$. The mRNA expression levels of $a$-SMA and vimentin were significantly increased by $1.68 \pm 0.08$ fold $(P=0.0007)$ and $3.39 \pm 0.36$ fold $(P=0.0014)$, respectively, in the induced group when compared to that of the control group. In short, although the expression of CK19 was not significantly decreased after 48 hours of co-culture, the expression of mesenchymal marker was still increased in the NRK-52E cells, thus resulting in phenotypic changes in these cells.

Immunofluorescence was used to analyze two epithelial cell markers, CK19 and E-Ca, and three mesenchymal markers, $\alpha$-SMA, desmin, and vimentin, in the NRK-52E cells. The scoring results of immunofluorescence staining are shown in Table 2. In the control group (Figure 4, B-F), NRK-52E cells were clearly positive for the epithelial cell markers CK19 and E-Ca. The CK19 staining was diffusely distributed in the cytoplasm, while the E-Ca staining mainly localized to the cell membrane. Staining for the mesenchymal cell marker a-SMA was absent, while the staining for desmin and vimentin was weakly positive.
The results of immunofluorescence staining of NRK-52E cells in the induction group showed that although the CK19 staining intensity was not significantly decreased compared with that in the control group, the fluorescence staining intensity of the other epithelial cell marker (E-Ca) was significantly decreased to almost negative (Figure 4, G-H). At the same time, NRK-52E cells in the induction group showed strong positive staining for mesenchymal cell markers ( $\alpha$-SMA, desmin, and vimentin) (Figure 4, I-K), which were diffusely distributed in the cytoplasm. Furthermore, in the induction group, vimentin immunofluorescence staining exhibited a large fibrous filamentous structure radially arranged in the nucleus periplasm.

The results showed that the cellular morphology changed when NRK-52E cells were co-cultured with freshly isolated thymocytes for 48 hours. Although the expression levels of some epithelial cell phenotypes were not significantly decreased, there was an evident increase in the expression levels of the mesenchymal cell phenotypes. This means that NRK$52 \mathrm{E}$ cells had undergone the EMT.

\section{Discussion}

Renal tubulointerstitial fibrosis is a common terminal pathway of almost all progressive chronic kidney diseases. The morphological manifestations of renal tubulointerstitial fibrosis include the atrophy of renal tubules, stromal sclerosis, loss of nephrons, and thickening of the arteriole wall..$^{20}$ The key effector cells in the pathogenesis of fibrosis are activated fibroblasts or myofibroblasts, which produce excessive extracellular matrix, including collagen, fibronectin, and laminin. ${ }^{5}$ The origin of these myofibroblasts has long been a subject of investigation and debate. ${ }^{21}$ Emerging evidence supports the concept that during renal injury, the tubular epithelial cells are capable of transdifferentiation into fibroblasts/myofibroblasts 
in a process known as the EMT. ${ }^{6}$ Although the role of tubular epithelial cell transdifferentiation in chronic renal fibrosis has been gradually recognized, the mechanism of initiation of this process is still not clear.

People who survive AKI and acute allograft rejection always develop chronic kidney diseases (CKD). The inappropriate repair mechanisms that persist following the acute stage further promote inflammation and fibrosis in the chronic stage of renal diseases, where infiltrated $\mathrm{T}$ lymphocytes play complex functions, which are still not clear. ${ }^{11,22}$ These phenomena suggest that $\mathrm{T}$ lymphocyte infiltration may be related to the progression of renal tubulointerstitial fibrosis. A recent report has revealed that the human effector $\gamma \delta$ T cells contribute to the fibrotic process, thus facilitating the progression to $\mathrm{CKD}$ in vivo. ${ }^{16}$ Regulatory $\mathrm{T}$ cells have also been reported to play important roles in pulmonary fibrosis by inducing the EMT. ${ }^{15}$ Moreover, $\mathrm{T}$ cells and macrophages may participate in the renal interstitial fibrosis via the EMT in the unilateral ureteral obstruction (UUO) model of neonatal mice. ${ }^{23}$ As there are many subtypes of $\mathrm{T}$ cells, they may contribute to the development of fibrosis, perhaps through the progression of EMT. Consequently, we postulated that even young T cells (regardless of the subtypes) may induce the tubular epithelial cells to transform into myofibroblasts.

We isolated fresh rat thymic-derived lymphocytes and treated them with PHA and ConA to induce proliferation and cytokine production. After activation, the percentages of thymic-derived lymphocytes in the G2 and S phases increased, the percentage of $\mathrm{CD}^{+}$mature $\mathrm{T}$ cells increased, and the production of IL-2 was also enhanced. T cells, in the activated state, can secrete a variety of cytokines, including IL- $2,{ }^{24}$ and IL-2 can further induce the EMT and extracellular matrix synthesis in many diseases. ${ }^{25}$ Therefore, the improved cell proliferation and enhanced IL-2 production was enough to verify the $\mathrm{T}$ cell activation.

To the best of our knowledge, so far, no one has reported that thymocytes induce the EMT of tubular epithelial cells. Zhao Chen et al. co-cultured human renal proximal tubular epithelial cells (HK-2 cells) with M2c macrophages. ${ }^{14}$ Their results revealed that E-Ca was downregulated, while $\alpha$-SMA and vimentin were upregulated in the HK-2 cells. Therefore, they concluded that $\mathrm{M} 2 \mathrm{c}$ macrophages have a promoting effect on the EMT of HK-2 cells. Our results showed that the induced NRK-52E cells almost completely lost their epithelial cell markers (including CK19 and E-Ca), and all the mesenchymal cell markers, including a-SMA, desmin, and vimentin were simultaneously expressed. Scratch assay also revealed that the cell migration abilities of these cells had improved. Although we didn't detect the ECM production of NRK-52E cells under stimulation, our results were enough to indicate that the prepared treatment medium, which was harvested from the rat thymocytes activated in vitro, can induce the EMT of NKR-52E cells. In our experiments, freshly isolated thymocytes induced the upregulation of mesenchymal cell markers in NRK-52E cells without a full reduction of some epithelial cell markers, such as CK19. This phenomenon has been reported as a partial EMT or pre-EMT, especially in vivo. ${ }^{26-28}$ This means that our results are consistent with what has been reported to happen to injured kidneys in vivo. Our results showed that activated rat thymocytes can induce the EMT, while freshly isolated thymocytes can induce a partial EMT in the rat renal tubular epithelial cells in vitro.

Law et al. indicate that the human tissue-resident mucosal-associated invariant $\mathrm{T}$ (MAIT) cells $\left(\mathrm{CD}^{+}, \mathrm{CD} 161^{+}\right)$in the kidney may contribute to the fibrotic process of CKD via complex interactions with human primary proximal tubular epithelial cells (PTECs). The in vitro study showed that the co-culture of cytotoxic mucosa-associated lymphoid tissue (MALT) cells with PTECs resulted in the elevation of cytokines secreted by MALT cells and necrosis of PTECs, ${ }^{29}$ but this study didn't test for the EMT of cells. It has long been confirmed that CD8 positive cytotoxicity $\mathrm{T}$ lymphocytes are the main immune cells invading the renal tubular cells in acute cell rejection after renal transplantation. ${ }^{30}$ Our results showed that the treatment medium harvested from activated rat thymocytes (mainly CD8 ${ }^{+} \mathrm{T}$ cells) can induce the EMT of renal tubular epithelial cells. It is suggested that the injury of renal tubule epithelial cells induced by the $\mathrm{CD}^{+} \mathrm{T}$ cell infiltration in acute "tubulitis" of renal transplantation can induce the transdifferentiation of renal epithelial cells to mesenchymal cells, thus exacerbating the fibrosis process in a vicious cycle and leading to the formation of long-term chronic renal fibrosis.

There have been reports that the EMT of renal tubular epithelial cells can be regulated by growth factors, cytokines, and hormones, among which TGF- $\beta 1$ is the most important profibrotic factor in the kidney and the most recognized EMT promoting factor, which normally functions at a dose of 10 ng/mL. ${ }^{31}$ However, the TGF- $\beta 1$ production was not promoted in the PHA- and ConA-induced thymocytes in our study, where the concentration was $382.03 \pm 48.07 \mathrm{pg} / \mathrm{mL}$ in the control group and $417.15 \pm 20.29 \mathrm{pg} / \mathrm{mL}$ in the stimulated group. Therefore, the treatment medium, which was harvested from the rat thymocytes activated in vitro, may induce the EMT of NKR-52E cells via IL-2 but not the TGF- $\beta 1$ pathway.

Since the inflammatory environment in vivo is extremely complex, where there can't be just one type of T cell involved, a complete simulation of the internal environment is almost impossible. One limitation of our study is that our experiment model didn't fully mimic the inflammation circumstantial environment in vivo. Our study just clarified the phenomenon that activated thymocytes can induce the EMT of NRK-52E cells, but the specific intrinsic mechanism involved in this process requires further research.

\section{Conclusion}

In summary, our results showed that the rat thymocytes activated in vitro (prominently the $\mathrm{CD}^{+} \mathrm{T}$ cells) can induce the EMT, while freshly isolated thymocytes can induce a partial EMT in the rat renal tubular epithelial cells. To the best of our knowledge, this phenomenon has not been reported before. As this transition represents an important mechanism of renal tubulointerstitial fibrosis, clinically active treatment of acute renal injury maybe the key to improve the prognosis of AKI and acute allograft rejection. 


\section{Conflicts of interest}

The authors report no conflicts of interest.

\section{Acknowledgments}

This work was supported by the Sichuan Provincial Commission of Health and Family Planning Project, under grant number 130177, and Sichuan Provincial People's Hospital Special Fund, under grant number 2020ZX01.

\section{References}

1. Loupy A, Haas M, Solez K, Racusen L, Glotz D, Soren D, et al. The Banff 2015 Kidney Meeting Report: Current Challenges in Rejection Classification and Prospects for Adopting Molecular Pathology. Am J Transplant. 2017;17:28-41.

2. Solez K, Colvin RB, Racusen LC, Sis B, Halloran PF, Brik PE, et al. Banff '05 Meeting Report: differential diagnosis of chronic allograft injury and elimination of chronic allograft nephropathy ('CAN'). Am J Transplant. 2007;7:518-26.

3. Granata S, Benedetti C, Gambaro G, Zaza G. Kidney allograft fibrosis: what we learned from latest translational research studies. J Nephrol. 2020;33:1201-11

4. Wynn TA. Common and unique mechanisms regulate fibrosis in various fibroproliferative diseases. J Clin Invest. 2007;117:524-9.

5. Sun YB, Qu X, Caruana G, Li J. The origin of renal fibroblasts/ myofibroblasts and the signals that trigger fibrosis. Differentiation. 2016; 92:102-7.

6. Cruz-Solbes AS, Youker K. Epithelial to Mesenchymal Transition (EMT) and Endothelial to Mesenchymal Transition (EndMT): Role and Implications in Kidney Fibrosis. Results Probl Cell Differ. 2017;60:345-72.

7. Liu Y. Epithelial to mesenchymal transition in renal fibrogenesis: pathologic significance, molecular mechanism, and therapeutic intervention. J Am Soc Nephrol. 2004;15:1-12.

8. Kriz W, Kaissling B, Le Hir M. Epithelial-mesenchymal transition (EMT) in kidney fibrosis: fact or fantasy? J Clin Invest. 2011;121:468-74.

9. Dellepiane S, Leventhal JS, Cravedi P. T Cells and Acute Kidney Injury: A Two-Way Relationship. Front Immunol. 2020;11:1546.

10. Aoki Y, Hamasaki Y, Satoh H, Matsui Z, Muramatsu M, Hamada R, et al. Long-term outcomes of pediatric kidney transplantation: A single-center experience over the past 34 years in Japan. Int J Urol. 2020;27:172-8.

11. Alarrayed S, El-Agroudy A, Al-Arrayed A, Ghareeb S, Farid E, Garadah T, et al. Why does kidney allograft fail? A long-term single-center experience. Saudi J Kidney Dis Transpl. 2011;22:818-24.

12. Zuk A and Bonventre JV, Acute Kidney Injury. Annu Rev Med. 2016;67: 293-307.

13. Haas M, Loupy A, Lefaucheur C, Roufosse C, Glotz D, Seron D, et al. The Banff 2017 Kidney Meeting Report: Revised diagnostic criteria for chronic active T cell-mediated rejection, antibody-mediated rejection, and prospects for integrative endpoints for next-generation clinical trials. Am J Transplant. 2018;18:293-307.12.

14. Chen Z, Dong F, Lu J, Wei L, Tian L, Ge H, et al. Polarized M2c macrophages have a promoting effect on the epithelial-to-mesenchymal transition of human renal tubular epithelial cells. Immunobiology. 2018; 223:826-33.
15. Xiong S, Pan X, Xu L, Yang Z, Guo R, Gu Y, et al. Regulatory T Cells Promote beta-Catenin--Mediated Epithelium-to-Mesenchyme Transition During Radiation-Induced Pulmonary Fibrosis. Int J Radiat Oncol Biol Phys. 2015;93:425-35.

16. Law BM, Wilkinson R, Wang X, Kildey K, Lindner M, Beagley K, et al. Effector gammadelta $\mathrm{T}$ cells in human renal fibrosis and chronic kidney disease. Nephrol Dial Transplant. 2019;34:40-8.

17. Baroni CD, Rigato P, Ruco L, Uccini S, Mineo T, Ricci C, et al. PHA and ConA lymphocyte response in normal, hyperplastic and neoplastic human thymus: morphologic and functional correlations. Cancer. 1980; 46:2055-61.

18. Ren F, Chen X, Hesketh J, Gan F, Huang K. Selenium promotes T-cell response to TCR-stimulation and ConA, but not PHA in primary porcine splenocytes. PLoS One. 2012;7:e35375.

19. Tan TK, Zheng G, Hsu TT, Wang Y, Lee VW, Tian X, et al. Macrophage matrix metalloproteinase- 9 mediates epithelial-mesenchymal transition in vitro in murine renal tubular cells. Am J Pathol. 2010;176:1256-70.

20. Maluf DG, Dunur CI, Suh JL, Lee JK, Cathro EP, King AL, et al. Evaluation of molecular profiles in calcineurin inhibitor toxicity post-kidney transplant: input to chronic allograft dysfunction. Am J Transplant. 2014;14:1152-63

21. Mack M, Yanagita M. Origin of myofibroblasts and cellular events triggering fibrosis. Kidney Int. 2015;87:297-307.

22. Gong L, Pan Q, Yang N. Autophagy and Inflammation Regulation in Acute Kidney Injury. Front Physiol. 2020;11:p576463.

23. Lange-Sperandio B, Trautmann A, Eickelberg O, Jayachandran A, Oberle S, Schmidutz F, et al. Leukocytes induce epithelial to mesenchymal transition after unilateral ureteral obstruction in neonatal mice. Am J Pathol. 2007;171:861-71.

24. Lo HY. Itk inhibitors: a patent review. Expert Opin Ther Pat. 2010;20: 459-69.

25. Jing R, Qi T, Wen C, Yue J, Wang G, Pei C, et al. Interleukin-2 induces extracellular matrix synthesis and TGF-beta2 expression in retinal pigment epithelial cells. Dev Growth Differ. 2019;61:410-8.

26. Sun KH, Chang Y, Reed AI, Sheppard D. alpha-Smooth muscle actin is an inconsistent marker of fibroblasts responsible for force-dependent TGFbeta activation or collagen production across multiple models of organ fibrosis. Am J Physiol Lung Cell Mol Physiol. 2016;310:L824-36.

27. Yuan Q, Tan RJ, Liu Y. Myofibroblast in Kidney Fibrosis: Origin, Activation, and Regulation. Adv Exp Med Biol. 2019;1165:253-83.

28. Lovisa S, LeBleu VS, Tampe B, Sugimoto H, Vadnagara K, Carstens JL, et al. Epithelial-to-mesenchymal transition induces cell cycle arrest and parenchymal damage in renal fibrosis. Nat Med. 2015;21:998-1009.

29. Law BMP, Wilkinson R, Wang X, Kildey K, Giuliani K, Beagley KW, et al. Human Tissue-Resident Mucosal-Associated Invariant T (MAIT) Cells in Renal Fibrosis and CKD. J Am Soc Nephrol. 2019;30:1322-35.

30. Robertson H, Wheeler J, Thompson V, Johnson JS, Kirby JA, Morley AR. In situ lymphoproliferation in renal transplant biopsies. Histochem Cell Biol. 1995;104:331-4.

31. Fan JM, Ng YY, Hill PA, Nikolic-Paterson DJ, Mu W, Atkins RC, et al. Transforming growth factor-beta regulates tubular epithelial-myofibroblast transdifferentiation in vitro. Kidney Int. 1999;56:1455-67. 